\title{
Effect of Cold Storage on Development of Habrobracon hebetor (Say) (Braconidae: Hymenoptera) Reared on Corcyra cephalonica Stainton (Lepidoptera: Pyralidae)
}

\author{
Atirach NOOSIDUM*, Weerachai SOMSRI and Angsumarn CHANDRAPATYA \\ Department of Entomology, Faculty of Agriculture, Kasetsart University, Bangkok 10900, Thailand
}

('Corresponding author’s e-mail: fagrarn@ku.ac.th)

Received: 23 March 2017, Revised: 1 March 2018, Accepted: 19 April 2018

\begin{abstract}
Habrobracon hebetor has been investigated as a successful biological control agent for larvae of pyralid moths in warehouses. Gaining new information on how to improve the storage procedure of $H$. hebetor under cold conditions could allow the development of approaches to maintain this parasitoid in pest management programs. This study investigated the effect of cold temperatures $\left(10\right.$ and $\left.15^{\circ} \mathrm{C}\right)$ on the development of $H$. hebetor pupae reared on Corcyra cephalonica, which was kept for up to 3 weeks. Mortality of $H$. hebetor pupae during cold storage in all treatments was $4-19 \%$. Mortality of $H$. hebetor adults emerging during cold storage at $10{ }^{\circ} \mathrm{C}(28 \%)$ and $15{ }^{\circ} \mathrm{C}(61 \%)$ was significantly observed at 21 days of storage, while other treatments were less than $4 \%$. Numbers of emerging adults after cold storage from 7 - 14 days were 89 - $96 \%$, and the female percentage ranged from $13-39 \%$. The number of eggs laid per female from the emerging females after cold storage for $7-14$ days was not significant as compared to the control treatment (43 - 53 eggs per female) after laying for $72 \mathrm{~h}$. The sex ratios of emerging adults in all cold storages and the control treatment at $72 \mathrm{~h}$ after emerging were not significant.
\end{abstract}

Keywords: Insect parasitoid, rice moth, cold storage, sex ratio, biological control

\section{Introduction}

Biological control programs, a significant part of integrated pest management (IPM) programs, have been one of the environmentally-friendly methods used in controlling insect pests since the $19^{\text {th }}$ century [1]. This control program has given an advantage mostly to users, consumers, and all non-target organisms, and it has been a promising alternative to pesticide application to control economically important insect pests [2]. The biological control method normally relies on predators, parasitoids, or pathogens which have efficiency in killing a specific pest during its entire life cycle. Several insect natural enemies, including predators and parasitoids, have been employed as bio-control agents, and various successful results have been reported all around the world [1-3]. Braconid wasps are parasitoid insects which normally cause insect mortality in natural fields, and many genera of Braconidae (e.g., Cotesia, Apanteles, and Habrobracon) are now playing important roles in biological control programs to manage various insect pests in several crops of worldwide organic farming [4]. Nowadays, $H$. hebetor (Say) is produced and sold commercially to control some stored-product moths [5].

Habrobracon hebetor (= Bracon hebetor Say) has long been known as an important biological control agent to inflict substantial mortality on various immature insects belonging to Order Lepidoptera $[6,7]$. This parasitoid is considered as one of the best potential biological control agents and a well-known polyphagous ectoparasitoid of many lepidopteran larvae infesting flour mills, warehouses, and food stores in storage facilities, especially the larvae of Family Pyralidae and Noctuidae [6,8-11]. Several researchers reported that the release of $H$. hebetor can deplete numbers of insect pests in both storage [6,8] and field 
http://wjst.wu.ac.th

conditions [12], such as the Mediterranean flour moth (Ephestia kuehniella Zeller), Indian meal moth (Plodia interpunctella (Hübner)), rice moth (Corcyra cephalonica (Stainton)), greater wax moth (Galleria mellonella (L.)), and army worm (Helicoverpa amigera (Hübner)), because of its high reproductive and development rate, short generation time, and wide range of host species $[6,7,10]$. The female $H$. hebetor prefers to parasitize the larval stage of its host and then lays eggs on or near the outer surface of the paralyzed host [5]. Larvae of $H$. hebetor hatch within 2 days after egg laying and then the larva feeds on its host until it becomes an adult [13].

However, the success of biological control programs of $H$. hebetor depends on various factors, such as the number of the insect pest population and the number of the parasitoid population in the management area [14]. Therefore, a huge number of the parasitoid population must be used for implementation in the management area to suppress the insect pest population at an economical level [7]. Mass rearing and handling processes are important for the implementation of the biological control method of $H$. hebetor. Its fitness and performance, such as survival, development, size, longevity, fecundity, and sex ratio, should be modified during mass production [15,16]. Moreover, the effects of different factors on the behavioral ecology of $H$. hebetor are elated to parasitism succession in optimizing mass production of the parasitoid in biological control programs [13,17]. Host density and storage techniques are necessary to improve the flexibility and efficiency in mass production of $H$. hebetor $[10,18]$.

C. cephalonica is normally used as one of the preferred diets for rearing H. hebetor in laboratory conditions for mass production of the parasitoid in many countries [7,19]. However, the rearing of $H$. hebetor on $C$. cephalonica larva has shown unsatisfying implementation results in biological control programs in Thailand. This wasp produces a lesser number of offspring in the next generation, and adults rapidly emerge from the pupal stage; thus, suitable host density and storage condition is still uncertain. The objective of this study was to evaluate the effect of cold temperatures on the storage of $H$. hebetor reared on $C$. cephalonica larva, in order to select suitable conditions for further development of mass rearing of this parasitoid.

\section{Materials and methods}

\section{Insect rearing}

\section{Corcyra cephalonica}

The target host used in this study, C. cephalonica, was originally obtained from the Bureau of Agricultural Commodities Promotion and Management, Department of Agricultural Extension (DOAE), Ministry of Agriculture and Cooperatives, Bangkok, Thailand, in 2015. The C. cephalonica colony was maintained on a diet of rice bran. Approximately 400 eggs were sprinkled into a rearing container $(23 \mathrm{~cm}$ diameter; $10 \mathrm{~cm}$ height) containing 1200 grams of the diet, and the lid covered and sealed with glue tape. Eggs hatched after 4 - 5 days, with all larvae fed on an artificial diet for 25 - 30 days before turning into pupae and becoming adults. Adults ( 1 - 2 days old) were collected from the stock culture and held in a cage made of Polyethylene net (225 mesh) for oviposition. Environmental conditions were $28.0 \pm 0.5^{\circ} \mathrm{C}$, $75 \pm 5 \% \mathrm{RH}$, and 12L: 12D photoperiod. Final instar larvae were used in all experiments.

\section{Habrobracon hebetor}

$H$. hebetor was obtained from the same place as C. cephalonica. This strain was previously used for a few years for the biological control of Opisina arenosella Walker, and was maintained in the laboratory on final instar larvae of C. cephalonica at the Department of Entomology, Kasetsart University, Thailand.

Adult parasitoids were introduced into a plastic container $(7 \mathrm{~cm}$ diameter; $4.5 \mathrm{~cm}$ height) containing C. cephalonica final instar larvae and a paper dipped in $20 \%$ honey, and the container then covered with a screen lid. Environmental conditions for rearing $H$. hebetor were the same as those used in rearing $C$. cephalonica. To obtain newly emerging parasitoids, adult female and male $H$. hebetor (3 couples) were released into a new rearing container with 5 C. cephalonica final instar larvae and removed after $24 \mathrm{~h}$. Each parasitized larva was incubated separately, and the resulting adult parasitoids were used in the experiments. 
http://wjst.wu.ac.th

\section{Effect of cold storage on development of $H$. hebetor}

Five last instar larvae of $C$. cephalonica were separately placed in a plastic cup ( $7 \mathrm{~cm}$ diameter; 4.5 $\mathrm{cm}$ height); then, 3 couples of $H$. hebetor adults were released into each cup. After 3 days, all $H$. hebetor were removed from the cups. All $C$. cephalonica cadavers, containing pupal stages of the ectoparasitoid from each cup, were transferred into a new cup and covered with aluminum foil to prevent water loss. Cups were kept under different conditions, consisting of 2 temperature levels $\left(10\right.$ and $\left.15{ }^{\circ} \mathrm{C}\right)$ with 3 cold storage periods $(7,14$, and 21 days). Cold conditions were provided by temperature-controlled incubators. Five replicates were allocated to the cold storage treatments, and each treatment was repeated twice. The control treatment (without cold storage) was kept in the same rearing conditions. The effects of temperature and the cold storage period on the quality of parasitoids were evaluated by measuring the percentage of insect emerging and their sex ratio.

\section{Egg laying and progeny production of diapause females after cold storage}

One last instar larva of $C$. cephalonica was placed in a plastic cup ( $7 \mathrm{~cm}$ diameter; $4.5 \mathrm{~cm}$ height). One couple of $H$. hebetor obtained from the previous study in each treatment ( 2 temperature levels with 3 cold storage periods) was released into the cup. The couple of $H$. hebetor was transferred daily to a new cup containing a new last instar larva of $C$. cephalonica for 3 days (7, 14, and 21 days). Five replicates were performed for each treatment, and the experiment was repeated twice. The effects of temperature and cold storage period on daily parasitization was evaluated by measuring the percentage of insect progeny and their sex ratio.

\section{Statistical analyses}

Data in all experiments were analyzed by analysis of variance (one-way ANOVA) using a statistical program $(\mathrm{R}$ version 3.0.1.) [20], and Tukey's test $($ alpha $=0.05)$ was employed to compare mean values of adult emergence and sex ratio across the different cold storages of $H$. hebetor. Two-way ANOVA with temperature and storage period as the fixed effects were used to determine if the interaction between temperature and storage period significantly affected mortality of parasitoids, adult emergence, and the number of egg laid following storage.

\section{Results and discussion}

Effect of cold storage on development of $H$. hebetor

The effect of cold storage on the development of $H$. hebetor reared on $C$. cephalonica were observed by measuring (1) the mortality of $H$. hebetor adults emerging during cold storage, (2) the mortality of $H$. hebetor pupae during cold storage, and (3) the percentage of $H$. hebetor females after cold storage. Mortality of $H$. hebetor adults emerging during cold storage indicated that the interaction between period and temperature was found $(F=11.59 ; \mathrm{df}=2,54 ; P<0.01)$. Two temperature levels $(10$ and $15^{\circ} \mathrm{C}$ ) and 3 periods of cold storage $(7,14$, and 21 days) had an effect on the mortality of $H$. hebetor adults emerging during cold storage $(F=4.50 ; \mathrm{df}=1,54 ; P=0.03$ and $F=75.87 ; \mathrm{df}=2,54 ; P<0.01$, respectively). Mortality of $H$. hebetor adults emerging during cold storage at 10 and $15{ }^{\circ} \mathrm{C}$ was significantly observed at 21 days of storage $(F=37.61 ; \mathrm{df}=6,63 ; P<0.01)$. Mortality of $H$. hebetor adults emerging during cold storage at $15{ }^{\circ} \mathrm{C}$ for 21 days was the highest $(61.34 \pm 3.90 \%)$, followed by treatment of $H$. hebetor adults emerging during cold storage at $10{ }^{\circ} \mathrm{C}$ for 21 days $(28.49 \pm 8.86 \%)$. Other treatments and the control treatment were not significant (Table 1). 
http://wjst.wu.ac.th

Table 1 Mortality of pupae and emerging adults of $H$. hebetor during cold storage at 10 or $15^{\circ} \mathrm{C}$ for 7 , 14 , and 21 days

\begin{tabular}{|c|c|c|c|}
\hline Stage & Storage temperature $\left({ }^{\circ} \mathrm{C}\right)$ & Storage length (day) & $\operatorname{Mean} \pm \operatorname{SE}(\%)^{1 /}$ \\
\hline \multirow[t]{7}{*}{ Pupa } & control & - & $5.14 \pm 2.10 \mathrm{a}$ \\
\hline & 10 & 7 & $3.33 \pm 2.22 \mathrm{a}$ \\
\hline & & 14 & $5.96 \pm 2.24 \mathrm{a}$ \\
\hline & & 21 & $19.77 \pm 3.51 \mathrm{~b}$ \\
\hline & 15 & 7 & $5.75 \pm 1.97 \mathrm{a}$ \\
\hline & & 14 & $9.69 \pm 1.89 \mathrm{a}$ \\
\hline & & 21 & $5.64 \pm 2.81 \mathrm{a}$ \\
\hline \multirow[t]{7}{*}{ Emerging adult } & control & - & $0.00 \pm 0.00 \mathrm{a}$ \\
\hline & 10 & 7 & $0.00 \pm 0.00 \mathrm{a}$ \\
\hline & & 14 & $4.79 \pm 2.79 \mathrm{a}$ \\
\hline & & 21 & $28.49 \pm 8.86 \mathrm{~b}$ \\
\hline & 15 & 7 & $0.00 \pm 0.00 \mathrm{a}$ \\
\hline & & 14 & $0.00 \pm 0.00 \mathrm{a}$ \\
\hline & & 21 & $61.34 \pm 3.90 \mathrm{c}$ \\
\hline
\end{tabular}

${ }^{1 /}$ Means \pm SE followed by the same letters in each stage are not significantly different, according to Tukey's test $(P>0.05)$

The interaction between period and temperature affected the mortality of $H$. hebetor pupae during cold storage $(F=7.91 ; \mathrm{df}=2,54 ; P<0.01)$. Two temperature levels had no effect on the mortality of $H$. hebetor pupae during cold storage $(F=0.45$; $\mathrm{df}=1,54 ; P=0.50)$, while 3 periods of cold storage affected the mortality of $H$. hebetor pupae during cold storage $(F=3.34$; $\mathrm{df}=2,54 ; P=0.04)$. Mortality of $H$. hebetor pupae during cold storage in all treatments was less than $20 \%(4.00-19.77 \%)$, and significant difference among treatments was found $(F=4.10 ; \mathrm{df}=6,63 ; P<0.01)$. Mortality of $H$. hebetor pupae during cold storage at $10{ }^{\circ} \mathrm{C}$ for 21 days was the highest, while other treatments were not significant difference from the control (Table 1).

The interaction between period and temperature affected the number of $H$. hebetor adults emerging after cold storage $(F=4.32 ; \mathrm{df}=2,54 ; P=0.02)$. Two temperature levels and 3 periods of cold storage had an effect on the number of $H$. hebetor adults emerging after cold storage $(F=5.20 ; \mathrm{df}=1,54 ; P=$ 0.03 and $F=131.68 ; \mathrm{df}=2,54 ; P<0.01$, respectively). Adult males of $H$. hebetor emerging after cold storage in both temperatures at 21 days of storage were significantly different from the control and other treatments $(F=28.04 ; \mathrm{df}=6,63 ; P<0.01)$. Only $33.02 \pm 3.72 \%$ of emerging adults was found in a treatment at $15{ }^{\circ} \mathrm{C}$ for 21 days of storage, and $51.74 \pm 6.68 \%$ of emerging adults was also found in a treatment at $10{ }^{\circ} \mathrm{C}$ for 21 days of storage. The percentage of emerging adults of other treatments ranged from $89.25-96.67 \%$, and there was no significant difference from the control $(F=55.40 ; \mathrm{df}=6,63 ; P<$ 0.01) (Table 2).

The interaction between period and temperature also affected the number of adult female $H$. hebetor emerging after cold storage $(F=10.96 ; \mathrm{df}=2,54 ; P<0.01)$. Two temperature levels had no effect on the number of adult female $H$. hebetor emerging after cold storage $(F=0.01$; $\mathrm{df}=1,54 ; P=0.93)$, while 3 periods of cold storage had an effect on the number of adult female $H$. hebetor emerging after cold storage $(F=11.10 ; \mathrm{df}=2,54 ; P<0.01)$. Numbers of adult female $H$. hebetor emerging after cold storage in all treatments $(26.18-39.54 \%)$ were not different from the control treatment $(32.63 \pm 4.19 \%)$, except for female percentages in the treatment of $15^{\circ} \mathrm{C}$ for 7 and 21 days of storage $(F=7.85$; df $=6,63 ; P<$ 0.01) (Table 2). 
http://wjst.wu.ac.th

Table 2 Number of emerging adults of $H$. hebetor after cold storage at 10 or $15^{\circ} \mathrm{C}$ for 7,14 , and 21 days

\begin{tabular}{|c|c|c|c|}
\hline Sex & Storage temperature $\left({ }^{\circ} \mathrm{C}\right)$ & Storage length (day) & Mean \pm SE $(\%)^{1}$ \\
\hline \multirow[t]{7}{*}{ Total alive adults } & control & - & $94.86 \pm 2.10 \mathrm{c}$ \\
\hline & 10 & 7 & $96.67 \pm 2.22 \mathrm{c}$ \\
\hline & & 14 & $89.25 \pm 2.55 \mathrm{c}$ \\
\hline & & 21 & $51.74 \pm 6.68 \mathrm{~b}$ \\
\hline & 15 & 7 & $94.25 \pm 1.97 \mathrm{c}$ \\
\hline & & 14 & $90.31 \pm 1.89 \mathrm{c}$ \\
\hline & & 21 & $33.02 \pm 3.72 \mathrm{a}$ \\
\hline \multirow{7}{*}{$\begin{array}{l}\text { Female percentage of alive } \\
\text { adults }\end{array}$} & control & - & $32.63 \pm 4.19 \mathrm{~b}$ \\
\hline & 10 & 7 & $39.54 \pm 4.36 \mathrm{~b}$ \\
\hline & & 14 & $27.92 \pm 2.05 \mathrm{ab}$ \\
\hline & & 21 & $36.41 \pm 4.51 \mathrm{~b}$ \\
\hline & 15 & 7 & $13.84 \pm 3.37 \mathrm{a}$ \\
\hline & & 14 & $26.18 \pm 4.25 \mathrm{ab}$ \\
\hline & & 21 & $62.62 \pm 10.57 \mathrm{c}$ \\
\hline
\end{tabular}

${ }^{1 /}$ Means \pm SE followed by the same letters in each stage are not significantly different, according to Tukey's test $(P>0.05)$

\section{Egg laying and progeny production of females after cold storage}

Numbers of egg laid by females emerging from pupae after storage at 10 and $15{ }^{\circ} \mathrm{C}$ varied with the 3 periods of cold storage; the interaction between period and temperature was not found in all 3 times (24, 48 and $72 \mathrm{~h})(F=0.21-1.41 ; \mathrm{df}=5,54 ; P>0.05)$. The results showed that 2 temperature levels had no effect on the number of eggs $(F=0.29-0.90$; df $=1,54 ; P>0.05)$, while 3 periods of cold storage affected the number of eggs $(F=11.20-15.31$; df $=2,54 ; P<0.01)$. Those females which laid more eggs after removal from cold storage still varied with periods of cold storage of 24 and $48 \mathrm{~h}$. Egg laying in all treatments of cold storage (9.00 - 14.10 eggs per female) were not significant as compared to the control treatment $(13.50 \pm 2.90$ eggs per female) after laying for $24 \mathrm{~h}$, except in the treatment of females stored at 10 and $15{ }^{\circ} \mathrm{C}$ for 21 days, with only $1.60 \pm 1.39$ and $3.70 \pm 1.54$ eggs per female found, respectively $(F=5.7$; df $=6,63 ; P<0.01)$. After laying for 48 and $72 \mathrm{~h}$, the number of eggs in the treatment of females stored at $10{ }^{\circ} \mathrm{C}$ and $15{ }^{\circ} \mathrm{C}$ for 21 days were significantly lower than the control treatment $(F=5.7 ; \mathrm{df}=6,63 ; P<0.01$ and $F=4.4 ; \mathrm{df}=6,63 ; P<0.01$, respectively). After $48 \mathrm{~h}$, the number of eggs in all treatments ranged from $11.30-34.20$ eggs per female. Females stored at $10^{\circ} \mathrm{C}$ and $15{ }^{\circ} \mathrm{C}$ for 21 days at $72 \mathrm{~h}$ laid only $23.40 \pm 4.90$ and $23.10 \pm 4.32$ eggs per female, respectively, while in other treatments, females laid 43.20 - 45.50 eggs per female (Table 3 ). 
http://wjst.wu.ac.th

Table 3 Number of eggs laid by $H$. hebetor females after cold storage at 10 or $15{ }^{\circ} \mathrm{C}$ for 7,14 , and 21 days

\begin{tabular}{|c|c|c|c|}
\hline Time & Storage temperature $\left({ }^{\circ} \mathrm{C}\right)$ & Storage length (day) & Mean \pm SE (egg per female) ${ }^{1}$ \\
\hline \multirow[t]{7}{*}{24} & control & - & $13.50 \pm 2.90 \mathrm{c}$ \\
\hline & 10 & 7 & $9.00 \pm 2.01 \mathrm{bc}$ \\
\hline & & 14 & $13.70 \pm 2.69 \mathrm{c}$ \\
\hline & & 21 & $1.60 \pm 1.39 \mathrm{a}$ \\
\hline & 15 & 7 & $11.80 \pm 2.37 \mathrm{bc}$ \\
\hline & & 14 & $14.10 \pm 3.05 \mathrm{c}$ \\
\hline & & 21 & $3.70 \pm 1.54 \mathrm{~b}$ \\
\hline \multirow[t]{7}{*}{48} & control & - & $29.00 \pm 4.18 b c$ \\
\hline & 10 & 7 & $26.00 \pm 3.36 \mathrm{bc}$ \\
\hline & & 14 & $34.20 \pm 2.69 \mathrm{c}$ \\
\hline & & 21 & $11.30 \pm 3.32 \mathrm{a}$ \\
\hline & 15 & 7 & $29.40 \pm 3.35 \mathrm{bc}$ \\
\hline & & 14 & $25.50 \pm 4.57 \mathrm{bc}$ \\
\hline & & 21 & $13.70 \pm 2.47 \mathrm{a}$ \\
\hline \multirow[t]{7}{*}{72} & control & - & $45.50 \pm 5.71 \mathrm{~b}$ \\
\hline & 10 & 7 & $45.70 \pm 3.84 \mathrm{~b}$ \\
\hline & & 14 & $53.70 \pm 5.22 \mathrm{~b}$ \\
\hline & & 21 & $23.40 \pm 4.90 \mathrm{a}$ \\
\hline & 15 & 7 & $47.90 \pm 6.09 \mathrm{~b}$ \\
\hline & & 14 & $43.20 \pm 7.96 \mathrm{~b}$ \\
\hline & & 21 & $23.10 \pm 4.32 \mathrm{a}$ \\
\hline
\end{tabular}

${ }^{1 /}$ Means \pm SE followed by the same letters in each time are not significantly different, according to Tukey's test $(P>0.05)$.

The number of $H$. hebetor progeny developing from the previous eggs showed that the number of male progeny was 3 times higher than female progeny at 24, 48, and $72 \mathrm{~h}$ in all treatments (Figures 1A 1F). At $24 \mathrm{~h}$ after emerging, the interaction between period and temperature affected the number of male progeny $(F=3.19 ; \mathrm{df}=2,54 ; P=0.04)$ (Figure 1A). Two temperature levels had no effect on the number of male progeny $(F=9.92 ; \mathrm{df}=1,54 ; P=0.36)$, while 3 periods of cold storage affected the number of male progeny $(F=1.28 ; \mathrm{df}=2,54 ; P=0.26)$. Significance in the number of male progeny was found in the control treatment $(10.80 \pm 2.48$ individuals $)$ compared with the treatments of $10{ }^{\circ} \mathrm{C}(0.30$ individuals $)$ and $15{ }^{\circ} \mathrm{C}(1.60 \pm 0.95$ individuals $)$ for 21 days $(F=6.1 ; \mathrm{df}=6,63 ; P<0.01)$. The other 2 times $(48$ and $72 \mathrm{~h})$ showed that the interaction between period and temperature had no effect on the number of male progeny $(F=2.87 ; \mathrm{df}=2,54 ; P=0.06$ and $F=3.06 ; \mathrm{df}=2,54 ; P=0.06)$ (Figures 1B 1C). The 2 temperature levels and 3 periods of cold storage had no effect on the number of male progeny $(F=0.25-2.80 ; \mathrm{df}=1,54 ; P>0.05$ and $F=2.96-4.70 ; \mathrm{df}=2,54 ; P>0.05$, respectively). Significance between the control treatment $(21.40 \pm 3.82$ individuals $)$ and other treatments $(8.40-24.50$ individuals $)$ was not found at $48 \mathrm{~h}$ after emerging, but male progeny in the treatment of $10{ }^{\circ} \mathrm{C}$ for 14 days $(24.50 \pm$ 4.49 individuals) was significantly higher than male progeny at $10{ }^{\circ} \mathrm{C}(8.40$ individuals $)$ and $15{ }^{\circ} \mathrm{C}(9.90$ \pm 1.86 individuals) for 21 days $(F=1.8 ; \mathrm{df}=6,63 ; P<0.01)$. However, no significant difference was observed in the number of male progeny $(20.20-35.10$ individuals $)$ at $72 \mathrm{~h}$ after emerging $(F=1.3 ; \mathrm{df}=$ $6,63 ; P=0.24)$.

The number of female progeny showed that interaction between period and temperature for 3 times $(24,48$ and $72 \mathrm{~h})$ was not found $(F=2.21 ; \mathrm{df}=2,54 ; P=0.11 ; F=1.09 ; \mathrm{df}=2,54 ; P=0.34$ and $F=$ $1.83 ; \mathrm{df}=2,54 ; P=0.16)$. Also, the 2 temperature levels and 3 periods of cold storage had no effect on 
http://wjst.wu.ac.th

the number of female progeny $(P>0.05)$. Numbers of female progeny in all treatments at $24 \mathrm{~h}(0.30-$ 2.70 individuals) were not significant $(F=1.8 ; \mathrm{df}=6,63 ; P=0.09)$. Significant differences between treatments were observed after 48 and $72 \mathrm{~h}(F=2.5 ; \mathrm{df}=6,63 ; P=0.03$ and $F=1.8 ; \mathrm{df}=6,63 ; P<$ 0.01 , respectively), but none of these were different from the control treatment. Especially, the number of female progeny from the treatment of $15^{\circ} \mathrm{C}$ for 7 days $(13.60 \pm 3.36$ individuals) was higher than the treatment of $10^{\circ} \mathrm{C}$ for 21 days (Figures 1D - 1F).

The sex ratios between male and female progeny in all treatments were not significant $(P>0.01)$ in the control treatment at 3 times. The interaction between period and temperature for 3 times $(24,48$, and $72 \mathrm{~h}$ ) were not found $(F=1.34 ; \mathrm{df}=2,54 ; P=0.26 ; F=1.02 ; \mathrm{df}=2,54 ; P=0.36$ and $F=0.74 ; \mathrm{df}=2$, $54 ; P=0.48)$. The 2 temperature levels and the 3 periods of cold storage had no effect on the sex ratios after cold storage $(P>0.05)$. However, the proportions of males in all treatments at 24,48 , and $72 \mathrm{~h}$ ranged from $0.50-0.89,0.59-0.92$, and $0.62-0.91$, respectively (Figures 2A - 2C).
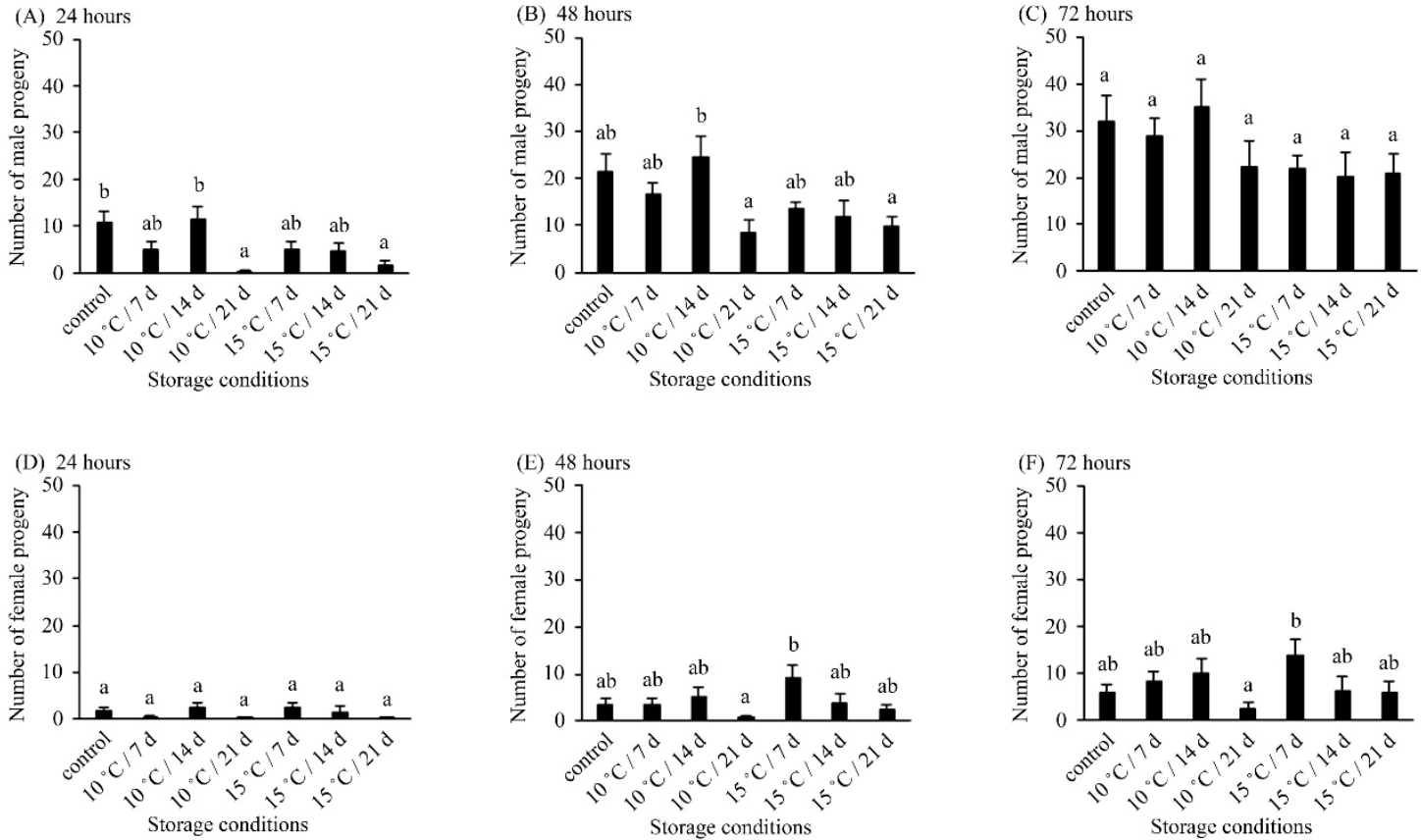

Figure 1 The effects of cold storage on male and female progeny of $H$. hebetor were tested for under various conditions: control (stored at room temperature), and stored at 10 or $15{ }^{\circ} \mathrm{C}$ for 7,14 , and 21 days; the average number of male progeny $(1 \mathrm{~A}-1 \mathrm{C})$ and female progeny $(1 \mathrm{D}-1 \mathrm{~F})$ of $H$. hebetor which emerged after cold storage for $24,48,72 \mathrm{~h}$. The same letters above the bars indicate treatments without significant differences, according to Tukey's test $(P>0.05)$. 

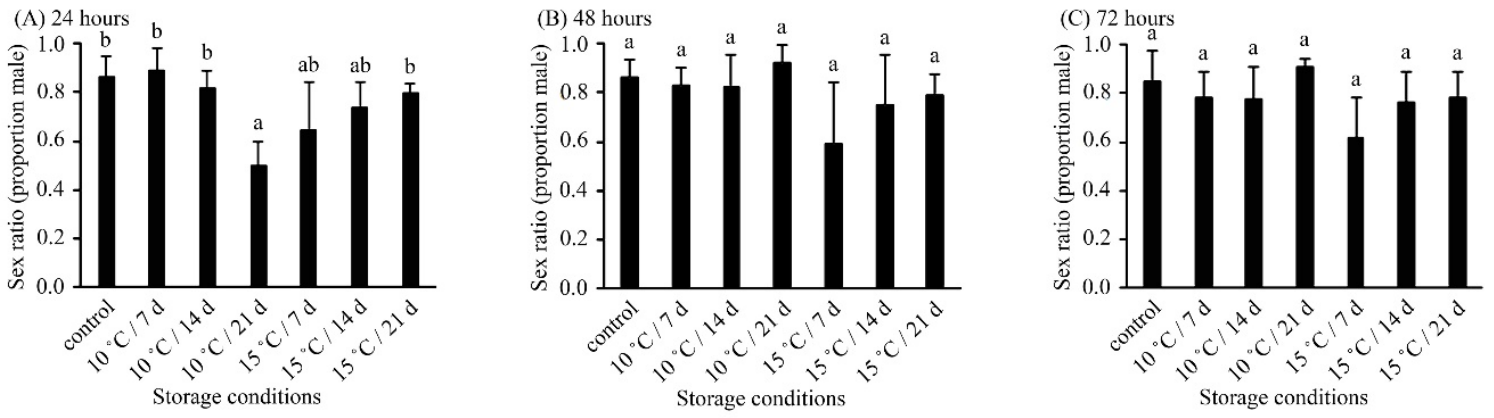

Figure 2 The effects of cold storage on sex ratio of $H$. hebetor were tested for under various conditions: control (stored at room temperature), and stored at 10 or $15^{\circ} \mathrm{C}$ for 7,14 , and 21 days; the sex ratio of $H$. hebetor which emerged after cold storage for 24,48 , and $72 \mathrm{~h}(2 \mathrm{~A}-2 \mathrm{C})$. The same letters above the bars indicate treatments without significant differences, according to Tukey's test $(P>0.05)$.

This study showed that $H$. hebetor can be effectively stored in cold conditions for up to 14 days, and can contribute to the improved use of $H$. hebetor as a biological control agent in pest management programs. Previous studies indicated that cold storage of $H$. hebetor for $14-21$ days did not seem to affect its survival and reproductive capabilities, which are traits that need to be maintained after cold storage [9,10,21]. A few studies reported that cold storage provides positive effects on the performance of $H$. hebetor rearing on $P$. interpunctella [9,21] and E. kuehniella [10], and studies supported that the storage of $H$. hebetor in cold temperatures was considered as a valuable tool to provide more flexibility and efficiency in mass production $[9,10,21,22]$.

The results of this study showed that most $H$. hebetor pupae that were stored at 10 and $15^{\circ} \mathrm{C}$ for up to 3 weeks were still alive during testing. Mortality during cold storage, egg laying, number of progeny produced, and sex ratio after removal from cold storage were similar to the control. These results were similar to Chen et al. [9] who indicated that $H$. hebetor reared at $20{ }^{\circ} \mathrm{C}$ and stored for up to 8 weeks did not differ in most of their mortality, longevity, egg laying, and the number of progeny produced after removal from cold storage from culture parasitoids. Mortality of adult $H$. hebetor emerging during cold storage at $15{ }^{\circ} \mathrm{C}$ was significantly observed to be up to $61 \%$ after 21 days of storage, and lower mortalities were found to be only $18 \%$. Mortality of $H$. hebetor pupae during cold storage in all treatments was $4-19 \%$. Similar to this result, the mortality of $H$. hebetor adults emerging during cold storage of parasitoids reared at 17.5 and $20{ }^{\circ} \mathrm{C}$, and then stored at $5{ }^{\circ} \mathrm{C}$ for 4 weeks, were up to $24-42 \%$, depending on different photoperiods. Mortality of males reared at $20{ }^{\circ} \mathrm{C}$ exceeded $80 \%$ after 8 weeks of storage, and no males survived after 16 weeks of cold storage [9]. The mortality might have been caused by the depletion of large resources during cold storage, resulting in reduced performance and accumulation of toxic metabolites that caused death or reduced fitness [9,23].

Egg laying after removal from cold storage of females reared at 10 and $15{ }^{\circ} \mathrm{C}$ varied with the period of cold storage. Egg laying of females emerging after cold storage was lower than that of cultured females in all treatments. Previous studies indicated that the number of eggs laid was always lower in stored insects than in cultured insects. This might have been because the parasitoids were recovering from chilling injuries after exposure to low temperatures [22,24], and eggs in the ovary might have been killed during storage [9]. In this study, egg laying cultures of $H$. hebetor averaged $23-53$ eggs per female in $C$. cephalonica at $72 \mathrm{~h}$, which was lower than the eggs obtained in some studies that found 253 eggs per female in Anagasta kuehniella Zeller (Lepidoptera: Pyralidae) [25], 326 eggs per female in Pectinophora gossypiella Saunders (Lepidoptera: Gelechiidae) [26], 78 eggs per female in Galleria mellonella L. (Lepidoptera: Pyralidae) [27], 66 eggs per female in Ephestia kuehniella Zeller (Lepidoptera: Pyralidae) [27], 400 eggs per female in Plodia interpunctella (Hübner) (Lepidoptera: Pyralidae) [21], and 311 eggs 
http://wjst.wu.ac.th

per female in P. interpunctella [9]. Egg laying in all treatments of cold storage was each up to 14, 34, and 45 eggs per female after laying for 24, 48, and $72 \mathrm{~h}$, respectively, and none of these were different compared to the control treatment. The differences in fecundity might be due to the different host species and, also, the different densities of parasitoids and larval hosts [9]. Fecundity in this study declined with increased cold storage period. Similarly, Chen et al. [21] reported that daily fecundity of $H$. hebetor declined when they were kept in cold storage longer than 30 days, and those female parents started to lay a few eggs on the second day. This phenomenon could be explained by the fact that parasitoids need to recover from chilling injuries after long exposure to low temperatures [22,24].

The percentages of female progeny produced by the females emerging after cold storage at 10 and $15{ }^{\circ} \mathrm{C}$ were $2-13 \%$, and they were always not different from the control $(5 \%)$. The percentage of female progeny for 21 days between cold storage treatment and culture treatment (13 vs. $30 \%$ ) after cold storage in this study was similar to Chen et al. [9], who revealed that the percentage of female emerging after cold storage at $5{ }^{\circ} \mathrm{C}$ was lower than cultured parasitoid (36 vs. $52 \%$ ). The sex ratios between males and females in all treatments were not significant in the control treatment at 3 periods, and ranged from 0.62 0.91 at $72 \mathrm{~h}$. Close to this experiment, Yu et al. [28] found that the progeny sex ratio of $H$. hebetor reared on $P$. interpuntella remained at 0.5 , while Rotary and Gerling [29] found $0.4 \%$ of $H$. hebetor female when $A$. kuehniella was provided as a host. This result was similar to several previous researchers, who found that the sex ratio of $H$. hebetor offspring were approximately $1: 1$ by using $P$. interpunctella as a host [9,30-32]. The differences in sex ratios among different studies might be due to the use of different hosts, host or parasitoid densities, and temperature conditions [9,21]. Although male percentages of adult $H$. hebetor emerging after cold storage in both temperatures after 21 days of storage significantly decreased, the presence of a male after cold storage did not affect the sex ratio of progeny. Female percentages of $H$. hebetor adults emerging after cold storage in all treatments were not different.

Storage proteins were synthesized before the insects entered diapause, then released into the insect hemolymph and remained throughout diapause. The proteins disappeared quickly after diapause was terminated $[9,33]$. However, previous studies indicated that increasing the longer cold storage of $H$. hebetor females resulted in a decline in parasitism, longevity, and fecundity of parents and offspring $[9,10,21,33]$. For example, the ability of $H$. hebetor to parasitize $P$. interpunctella larvae declined with increasing cold storage period, and $H$. hebetor parents stored for 70 days and allowed to parasitize $P$. interpunctella larvae for $72 \mathrm{~h}$ caused only $44 \%$ mortality, whereas control parents achieved $90 \%$ mortality [21]. The offspring declined to increase in the cold storage period because living organisms had limited resources, which were spent on growth, reproduction maintenance [34], and maternal aging. Previous studies had suggested that $H$. hebetor might overwinter in the adult stage [9,10,21], while our data showed that $H$. hebetor adults could survive up to 21 days at 10 and $15^{\circ} \mathrm{C}$ during the pupal stage. Heat shock proteins (HSPs) were expressed in most organisms in response to a wide range of stressful environmental conditions [34]. HSPs increase when cells are exposed to abnormal temperatures or other stress conditions [34,35]. Because of this mechanism, oleic acid levels were increased, which helped cell membranes maintain their liquid crystalline state, and promoted cellular survival at low temperatures [36]. Another reason was an increasing number of fat bodies, which might help an insect to survive at low temperatures by serving as an organ for energy storage and utilization [37,38].

\section{Conclusions}

Our results showed that the pupal stage of $H$. hebetor can be stored at 10 and $15{ }^{\circ} \mathrm{C}$ for up to 2 weeks without adversely affecting the performance of the parasitoid. Gaining new information on how to improve the performance of $H$. hebetor under cold conditions could lead to the development of approaches to keep and release this parasitoid in the agricultural field. This research proved that the use of H. hebetor as a biological control agent in pest management programs can be improved. Further research needs to be conducted on field performance of $H$. hebetor to improve performance after long-term cold storage. 
http://wjst.wu.ac.th

\section{Acknowledgements}

This research was supported by the Kasetsart University Research and Development Institute (Grant\# R-M 2.55). We also thank Dr. Watcharapong Chumchuen, Dr. Sheila Villamor, and Sirirut Mangtab for their valuable assistance.

\section{References}

[1] P DeBach and D Rosen. Biological Control by Natural Enemies. Cambridge University Press, Cambridge, UK, 1991.

[2] WG Ware. Complete Guide to Pest Control With and Without Chemicals. Thomson Publications. Fresno, California, 1980.

[3] DL Mahr, P Whitaker and N Ridgway. Biological Control of Insects and Mites, An Introduction to Beneficial Natural Enemies and Their Use in Pest Management. Department of Entomology University of Wisconsin-Madison, Cooperative Extension Publishing, Madison, WI, 2008.

[4] J Benson, A Pasquale, RV Driesche and J Elkinton. Assessment of risk posed by introduced braconid wasps to Pieris virginiensis, a native woodland butterfly in New England. Biol. Control. 2003; 26, 83-93.

[5] MN Ghimire and TW Phillips. Suitability of different lepidopteran host species for development of Bracon hebetor (Hymenoptera: Braconidae). Environ. Entomol. 2010; 39, 449-58.

[6] DW Keever, MA Mullen, JW Press and RT Arbogast. Augmentation of natural enemies for suppressing two major insect pests in stored farmer's stock peanuts. Environ. Entomol. 1986; 15, 767-77.

[7] MS Alam, MZ Alam, SN Alam, MR Miah, MI Mian and MM Hossain. Biology of Bracon hebetor reared on wax moth (Galleria mellonella) larvae. Persian. Gulf. Crop. Protect. 2014; 3, 54-62.

[8] JW Press, LD Cline and BR Flaherty. A comparison of two parasitoids, Bracon hebetor (Hymenoptera: Braconidae) and Venturia canescens (Hymenoptera: Ichneumonidae), and a predator Xylocoris flavipes (Hemiptera: Anthocoridae) in suppressing residual populations of the almond moth, Ephestia cautella (Lepidoptera: Pyralidae). J. Kansas. Entomol. Soc. 1982. 55, 125-8.

[9] $\mathrm{H}$ Chen, H Zhang, KY Zhu and J Throne. Performance of diapausing parasitoid wasps, Habrobracon hebetor, after cold storage. Biol. Control. 2013. 64, 186-94.

[10] Z Mousapour, A Alireza and A Habib. Effect of cold storage of pupae parasitoid wasp, Habrobracon hebetor (Say) (Hymenoptera: Braconidae), on its efficiency. Arch. Phytopathol. Plant Protect. 2014; 47, 966-72.

[11] M Mansour. Effects of gamma radiation on the Mediterranean flour moth, Ephestia kuehniella Zeller, mature larvae and acceptability of irradiated larvae by Bracon hebetor Say females. J. Stored Prod. Res. 2015; 60, 43-7.

[12] M Imam, A Uwais, U Namat, A Akbar and T Ahmat. Influence of Habrobracon hebetor on Helicoverpa armigera in southern Xinjiang. Nat. Enem. Insect. 2007; 29, 12-5.

[13] D Saadat, AR Bandani and M Dastranj. Comparison of the developmental time of Bracon hebetor (Hymenoptera: Braconidae) reared on five different lepidopteran host species and its relationship with digestive enzymes. Eur. J. Entomol. 2014; 111, 495-500.

[14] R Stouthamer, RF Luck and JH Werren. Genetics of sex determination and the improvement of biological control using parasitoids. Environ. Entomol. 1992; 21, 427-35.

[15] J Karimzadeh and DJ Wright. Bottom-up cascading effects in a tritrophic system: Interactions between plant quality and host-parasitoid immune responses. Ecol. Entomol. 2008; 33, 45-52.

[16] J Karimzadeh, J Hardie and DJ Wright. Plant resistance affects the olfactory response and parasitism success of Cotesia vestalis. J. Insect Behav. 2013; 26, 35-50.

[17] H Faal-Md-Ali and P Shishehbor. Biological parameters of Bracon hebetor (Hym.: Braconidae) parasitizing Ephestia kuehniella (Lep.: Pyralidae): Effect of host diet. J. Crop. Prot. 2013; 2, 411-9. 
http://wjst.wu.ac.th

[18] RA Leopold. Cold Storage of Insects for Integrated Pest Management. In: GJ Hallman and DL Denlinger (Eds.). Temperature Sensitivity in Insects and Application in Integrated Pest Management. Westview Press, Boulder, 1998, p. 235-67.

[19] PK Nikim and CV Powar. Life tables and intrinsic rate of natural increase of Bracon hebetor (Say) (Hymenoptera: Braconidae) population on Corcyra cephalonica (Stainton) (Lepidoptera: Pyralidae), a key parasitoid of Helicoverpa armigera (Hübner) (Lepidoptera: Noctuidae). J. App. Entomol. 1993; 115, 210-13.

[20] R Core Team. R: A Language and Environment for Statistical Computing. R Foundation for Statistical Computing. Available at: http://www.R-project.org, accessed July 2016.

[21] H Chen, P George, B Opit, PA Sheng and H Zhang. Maternal and progeny quality of Habrobracon hebetor Say (Hymenoptera: Braconidae) after cold storage. Biol. Control. 2011; 58, 255-61.

[22] RA Leopold, RR Rojas and PW Atkinson. Post pupariation cold storage of three species of flies: Increasing chilling tolerance by acclimation and recurrent recovery periods. Cryobiology 1998; 36, 213-24.

[23] KB Storey and JM Storey. Freeze tolerance in animals. Physiol Rev. 1988; 68, 27-84.

[24] HV Danks. Insect Dormancy: An Ecological Perspective. Vol. I. Biological Survey of Canada (Terrestrial Artropods), Ottawa, 1987.

[25] MS Clark and MR Worland. How insects survive the cold: Molecular mechanisms - A review. $J$. Comp. Physiol. B. Biochem. Syst. Environ. Physiol. 2008; 178, 917-33.

[26] CG Jackson and GD Butler. Development time of three species of Bracon (Hymenoptera: Braconidae) on the pink bollworm (Lepidoptera: Gelechiidae) in relation to temperature. Ann. Entomol. Soc. Am. 1984; 77, 539-42.

[27] AM Masood and H Chi. Demography of Habrobracon hebetor (Hymenoptera: Braconidae) on two pyralid hosts (Lepidoptera: Pyralidae). Ann. Entomol. Soc. Am. 2006; 99, 84-90.

[28] SH Yu, MI Ryoo, JH Na and WI Choi. Effect of host density and the sex ratio of progeny of Bracon hebetor (Hymneoptera: Braconidae). J. Stored. Prod. Res. 2003; 39, 385-93.

[29] N Rotary and D Gerling. The influence of some external factors upon the sex ratio of Bracon hebetor Say (Hymenoptera: Braconidae). Environ. Entomol. 1973; 2, 134-8.

[30] JA Reinert and EW King. Action of Bracon hebetor Say as a parasite of Plodia interpunctella at controlled densities. Ann. Entomol. Soc. Am. 1971; 64, 1335-40.

[31] PJ Ode, MF Antolin and MR Strand. Constrained oviposition and female biased sex allocation in a parasitic wasp. Oecologia 1997. 109, 547-55.

[32] DL Denlinger. Regulation of diapause. Annu. Rev. Entomol. 2002; 47, 93-122.

[33] SC Stearns. Life-history tactics: A review of the ideas. Quart. Rev. Biol. 1976; 51, 3-47.

[34] CP Chen, RE Lee and DL Denlinger. Cold shock and heat shock: A comparison of the protection generated by brief pretreatment at less severe temperatures. Physiol. Ent. 1991; 16, 19-26.

[35] JP Rinehart, A Li, GD Yocum, RM Robich, SA Hayward and DL Denlinger. Up-regulation of heat shock proteins is essential for cold survival during insect diapause. Proc. Natl. Acad. Sci. USA. 2007; 104, 11130-7.

[36] MR Michaud. 2007, Molecular Physiology of Insect Low Temperature Stress Responses. Ph. D. Dissertation. Ohio State University, Columbus, Ohio.

[37] NH Haunerland and PD Shirk. Regional and functional differentiation in the insect fat body. Annu. Rev. Entomal. 1995; 40, 121-45.

[38] EL Arrese and JL Soulages. Insect fat body: Energy, metabolism, and regulation. Annu. Rev. Entomol. 2010; 55, 207-25. 